\title{
KESIAPAN INDUSTRI KECIL DAN MENENGAH DALAM MENGHADAPI REVOLUSI INDUSTRI 4.0
}

\author{
*Anna Widayani ${ }^{1}$, Dwi Ariani Finda Yuniarti ${ }^{2}$ \\ ${ }^{1}$ Akademi Komunitas Negeri Putra Sang Fajar Blitar, Indonesia \\ ${ }^{2}$ Akademi Komunitas Negeri Pacitan, Indonesia \\ *e-mail: annawidayani@akb.ac.id
}

\begin{abstract}
This study aims to determine the readiness of small and medium industries in facing the industrial revolution 4.0 in small and medium industries in the city of Blitar. This research uses a quantitative approach with this type of explanatory research. The number of samples in this study was 97 small and medium industry players in the food and beverage sub-sector in the city of Blitar. The results showed that the Average Variance Extracted (AVE) value for the Organizational Management variable is 0,767; People and Culture variable is 0,808 ; Product and Service variable is 0,705 ; Technology variable is 0,709 and the Factory Operation variable is 0,705 . This means that these five variables have a positive and significant effect on the readiness of small and medium industries in facing the industrial revolution 4.0.
\end{abstract}

Keyword: Readiness, Small and Medium Industry, Industrial Revolution 4.0.

\begin{abstract}
Abstrak: Penelitian ini bertujuan untuk mengetahui kesiapan industri kecil dan menengah dalam menghadapi revolusi industri 4.0 pada industri kecil dan menengah di kota Blitar. Penelitian ini menggunakan pendekatan kuantitatif dengan jenis penelitian explanatory research. Jumlah sampel dalam penelitian ini yaitu 97 pelaku industri kecil dan menengah subsektor makanan dan minuman di kota Blitar. Hasil penelitian menunjukkan bahwa nilai Average Variance Extracted (AVE) untuk variabel Manajemen Organisasi sebesar 0,767; variabel Orang dan Budaya sebesar 0,808; variabel Produk dan Layanan sebesar 0,705; variabel Teknologi sebesar 0,709 dan variabel Operasi Pabrik sebesar 0,705. Artinya kelima variabel tersebut berpengaruh positif dan signifikan terhadap kesiapan industri kecil dan menengah dalam menghadapi revolusi industri 4.0.
\end{abstract}

Kata Kunci: Kesiapan, Industri Kecil dan Menengah, Revolusi Industri 4.0.

\section{PENDAHULUAN}

Saat ini Indonesia memasuki era revolusi industri 4.0. Revolusi industri 4.0 mengacu padatahap perkembangan dan pengelolaan seluruh proses rantai nilai dalam industri. Istilah Industri 4.0 pertama kali di Jerman tepatnya pada acara Hannover Fair di tahun (Kagermann \& Lukas, Wolf-Dieter Wahlster, 2011). Tujuan dari revolusi industri 4.0 untuk meningkatkan daya saing industri suatu negara dalam menghadapi pasar global yang dinamis. Hal tersebut diakibatkan oleh semakin pesatnya perkembangan dan pemanfataan teknologi digital di berbagai aspek (Fathul, 2007; Walczuch, et al, 2007; Haug, et al, 2011).

Revolusi industri merupakan perubahan cara hidup dan proses kerja dengan memanfaatkan kemajuan teknologi informasi, mengintregrasikan antara kehidupan 
dengan dunia digital yang dapat memberikan dampak bagi seluruh disiplin ilmu, ekonomi, sosial, industri, seni dan pemerintah. Menurut Sommer (2015) Kesiapan dan kemampuan untuk menghadapi tantangan revolusi Industri 4.0 ada di beberapa bagian yang sangat bergantung pada ukuran perusahaan. Semakin kecil UKM, semakin tinggi risiko mereka akan menjadi korban, bukan penerima manfaat revolusi ini. Dampak pada Industri di Indonesia mendorong pemerintah menerapkan Industri 4.0 dengan memanfaatkan peluang di era tersebut. Maka diperlukan adanya pendekatan dan kemampuan baru untuk membangun suatu sistem produksi yang berinovatif dan berkelanjutan (Kementerian Perindustrian RI, 2017).

Teknologi informasi yang berkembang secara pesat mengalami terobosan baru dalam bidang teknologi. Survei yang dilakukan oleh OECD (1993) menemukan bahwa adopsi Teknologi Informasi oleh Usaha kecil dan menengah masih rendah dibandingkan dengan perusahaan besar lainnya. Selain itu, Pengembangan Usaha kecil dan menengah dalam memasuki revolusi industri 4.0, diperlukan juga sebuah kesiapan usaha kecil dan menengah. Kesiapan merupakan sesuatu hal yang penting dalam mengembangkan minat usaha kecil dan menengah, karena dengan kesiapan berarti seseorang dapat dikatakan mampu untuk melakukan tindakan walaupun banyak resiko yang harus dihadapi. Menurut Lai, Kan, \& Ulhas (2012), makna kesiapan adalah suatu konsep perubahan yaitu suatu konsep pengembangan dan pergerakan. Konsep kesiapan tidak hanya mengenai kematangan fisik tetapi juga kombinasi dari tekanan emosi dan situasi sebagai akibat proses pembelajaran lingkungan dan hasil dari operasi yang baru. Dalam menilai kesiapan suatu UKM dalam mengadopsi inovasi baru merupakan syarat penting untuk berkembang dan mengikuti perkembangan pasar, teknologi informasi dan komunikasi juga sangat berperan penting pada dunia industri dan bisnis. E-readiness merupakan salah satu yang digunakan untuk mengevaluasi kesiapan suatu usaha atau industri dengan cara terintegrasi untuk mengadopsi, memanfaatkan, dan menggunakan teknologi informasi, sehingga dapat dikembangkan dalam merasionalisasikan suatu tindakan, meningkatkan daya saing, dan mengelola sumber daya secara lebih efisien.

Menurut Urata dalam Sulistyastuti (2004) Peran Penting Usaha Kecil, dan Menengah di Indonesia diantaranya yaitu: (1) Usaha kecil dan menengah (UKM) 
sebagai aktor utama dalam kegiatan ekonomi yang ada di Indonesia, (2) UKM sebagai penyedia kesempatan kerja, (3) UKM menciptakan Pasara dan Inovasi yang fleksibilitas antar kegiatan perusahaan, (4) Sebagai aktor penting dalam pengembangan ekonomi daerah/lokal dan pengembangan masyarakat, (5) Memberikan kontribusi untuk meningkatkan ekspor di bidang non migas. Sedangkan menurut Tambunan dalam (Sulistyastuti, 2004) menyebutkan bahwa yang mampu untuk mereduksi adanya ketimpangan pendapatan (reducing income inequality) terutama di Negara yang sedang berkembang adalah usaha kecil dan menengah.

Tabel 1 Kelompok Industri Kecil dan Menengah Kota Blitar

\begin{tabular}{clc}
\hline No & \multicolumn{1}{c}{ Subsektor } & Jumlah \\
\hline 1. & Industri Makanan, Minuman, dan Tembakau & 2.896 \\
\hline 2. & Industri Tekstil, Pakaian Jadi, dan Kulit & 509 \\
\hline 3. & Industri Kayu, Bambu, dan Peralatan Rumah Tangga & 592 \\
\hline 4. & $\begin{array}{l}\text { Industri Kertas dan Barang-Barang dari Kertas, } \\
\text { Percetakan, dan Penerbitan }\end{array}$ & 62 \\
\hline 5. & Industri Barang dari Logam, Mesin, dan Peralatannya & 361 \\
\hline 6. & Industri Pengolahan lainnya & 391 \\
\hline & Jumlah & $\mathbf{4 . 8 8 1}$ \\
\hline
\end{tabular}

Sumber: Dinas Perindustrian dan perdagangan Kota Blitar (di update 2020)

Berdasarkan data perkembangan Industri kecil dan menengah bahwa jumlah unit usaha yang ada di Kota Blitar selalu mengalami peningkatan setiap tahunnya. Data empat tahun terakhir yang ada di Kota Blitar jumlah unit usaha meningkat pada tahun 2018. Penyerapan tenaga kerja pada tahun 2017 menyerap sebanyak 12.227 orang dan pada tahun 2018 naik menjadi 13.763 tenaga kerja sesuai dengan grafik di bawah ini :

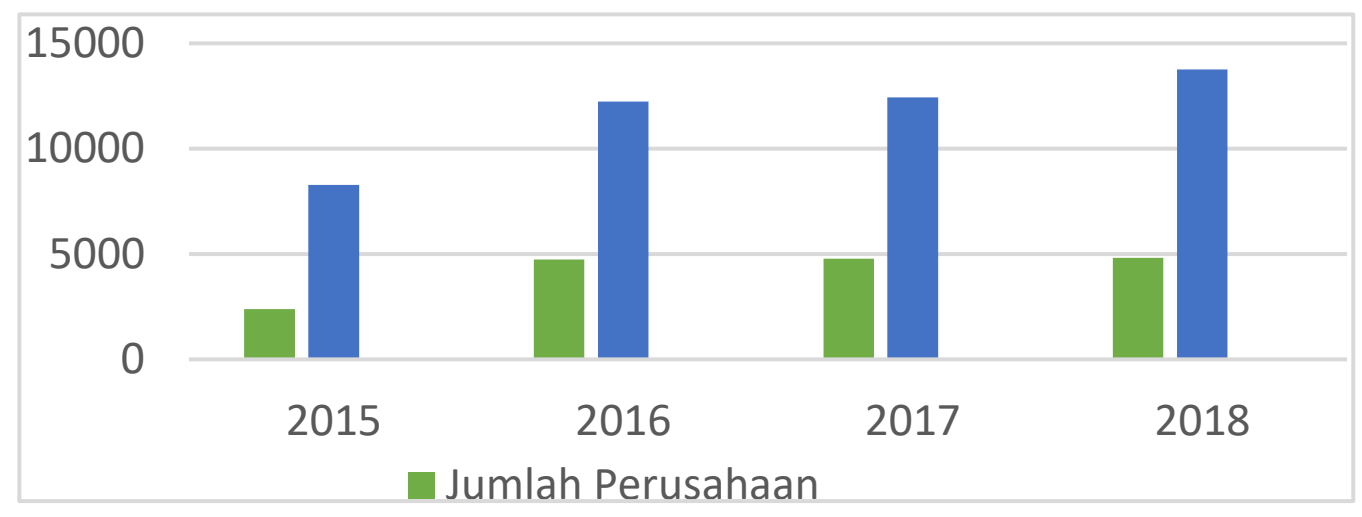

Gambar 1. Jumlah Unit Usaha Industri dan Tenaga Kerja Kota Blitar 
Sumber: Dinas Perindustrian dan Perdagangan Kota Blitar (di update 2019)

Adapun Karakteristik industri kecil menengah yaitu berskala mikro, yang tersebar di seluruh Indonesia, berupa padat karya, investasi yang relatifkecil dengan menghasilkan nilai tambah tinggi menggunakan teknologi yang masih sederhana sampai terbarukan, dantidak memerlukan keterampilan yang tinggi, dapat menciptakan sumber wirausaha baru, memiliki tingkat fleksibilitas yang tinggi dalam mengantisipasi perubahan pasar dan tahan terhadap timbulnya krisis ekonomi yang ada (Dirjen IKM,2006). Menurut (Irianto, 2017) tantangan industri 4.0 adalah (1) diversifikasi dan penciptaan lapangan kerja; (2) kesiapan industri; (3) tenaga kerja terpercaya; dan (4) kemudahan pengaturan sosial budaya. Adapun peluang industri 4.0 adalah (1) investasi pada teknologi; (2) integrasi Usaha Kecil Menengah (UKM) dan kewirausahaan; (3) basis industri yang kompetitif; dan (4) inovasi ekosistem.

Menurut Deputi Koordinasi Ekonomi Kreatif, Kewirausahaan, dan Daya Saing Koperasi, UKM bahwa dalam menghadapi revolusi Industri 4.0 membutuhkan SDM yang unggul dan andal sesuai kebutuhan usaha dan industri. Untuk dapat beradaptasi dengan perubahan pada revolusi industry 4.0(Sani \& Wiliani, 2019; Stentoft, et al, 2019) (Sani, et al, 2017; Stentoft, et al, 2019). Penggunaan teknologi informasi merupakan sebuah kegagalan, yang akan memberatkan secara finansial dan akan mempengaruhi keberlangsungan operasi bisnis itu sendiri (Sani, et al 2018). Alasan kesiapan dan peran signifikan dari penggunaan teknologi informasi dalam berbagai jenis industri akan menjadi tantangan baru bagi UKM. Berdasarkan uraian di atas, maka peneliti sangat tertarik untuk melakukan suatu penelitian dengan judul "Kesiapan Industri Kecil dan Menengah dalam Menghadapi Revolusi Industri 4.0"

\section{METODE PENELITIAN}

Jenis penelitian yang digunakan adalah explanatory research dengan pendekatan kuantitatif. Data dikumpulkan dengan menggunakan kuesioner. Jawaban kuesioner diukur dengan menggunakan skala likert, dengan bobot paling tinggi 5 dan paling rendah 1 . Pengujian instrumen penelitian dilakukan dengan menggunakan uji validitas dan reliabilitas. 
Populasi dalam penelitian ini adalah Industri Kecil dan Menengah Sektor Makanan dan minuman di Kota Blitar. Teknik pengambilan sampel adalah dengan proporsional random sampling dengan jumlah sampel 97 Industri kecil dan Menengah. Teknik analisa yang digunakan adalah analisis deskriptif dan inferensial dengan metode SEM-PLS. Model pengukuran (outer model) berfungsi untuk mengetahui hubungan antara indikator dengan variabel laten (Jogiyanto, 2007).

Adapun variabel dalam penelitian ini adalah sebagai berikut;

\begin{tabular}{|c|c|c|}
\hline Variabel & Item Penelitian & Referensi \\
\hline \multirow{3}{*}{$\begin{array}{l}\text { Manajemen } \\
\text { dan } \\
\text { Organisasi }\end{array}$} & $\begin{array}{l}\text { Pelaku IKM selalu melakukan kebijakan berinovasi } \\
\text { dalam meningkatkan kesiapannya memasuki } \\
\text { revolusi industri } 4.0\end{array}$ & \multirow{15}{*}{$\begin{array}{l}\text { Kementrian } \\
\text { Perindustrian } \\
\text { Republik } \\
\text { Indonesia } \\
\text { (2019), } \\
\text { Lokuge } \\
(2019)\end{array}$} \\
\hline & $\begin{array}{l}\text { Strategi yang dirumuskan oleh pelaku IKM relevan } \\
\text { dengan kesiapan menuju revolusi industri } 4.0\end{array}$ & \\
\hline & $\begin{array}{l}\text { IKM selalu mempertimbangkan investasi untuk } \\
\text { meningkatkan kesiapan memasuki revolusi industri } \\
4.0\end{array}$ & \\
\hline \multirow{3}{*}{$\begin{array}{l}\text { Orang dan } \\
\text { Budaya }\end{array}$} & $\begin{array}{l}\text { Budaya kerja IKM di Kota Blitar diarahkan siap } \\
\text { memasuki revolusi industri } 4.0\end{array}$ & \\
\hline & $\begin{array}{l}\text { IKM selalu terbuka untuk mengikuti perubahan } \\
\text { karena perkembangan teknologi sehingga siap } \\
\text { memasuki revolusi industri } 4.0\end{array}$ & \\
\hline & $\begin{array}{l}\text { IKM di kota Blitar selalu menerima masuknya } \\
\text { teknologi baru sehingga siap memasuki revolusi } \\
\text { industri } 4.0\end{array}$ & \\
\hline \multirow{3}{*}{$\begin{array}{l}\text { Produk dan } \\
\text { Layanan }\end{array}$} & $\begin{array}{l}\text { Layanan basis data yang dilakukan IKM berupa } \\
\text { layanan basis data yang terhubung dengan internet }\end{array}$ & \\
\hline & $\begin{array}{l}\text { IKM selalu melakukan perbaikan terutama pada } \\
\text { desain produk untuk siap memasuki relovusi industri } \\
4.0\end{array}$ & \\
\hline & $\begin{array}{l}\text { Produk yang dihasilkan oleh IKM merupakan } \\
\text { produk sesuai dengan keinginan pelanggan. }\end{array}$ & \\
\hline \multirow{3}{*}{ Teknologi } & $\begin{array}{l}\text { Tidak sulit bagi IKM untuk mengakses internet dan } \\
\text { teknologi baru yang menopang kegiatan inovasi } \\
\text { untuk siap menghadapi revolusi industri } 4.0 \text {. }\end{array}$ & \\
\hline & $\begin{array}{l}\text { IKM memasarkan produknya berbasis digitalisasi } \\
\text { (digital marketing) yang lebih potensial dan efektif } \\
\text { dalam menjangkau konsumen sehingga siap dalam } \\
\text { menghadapi revolusi industri } 4.0\end{array}$ & \\
\hline & $\begin{array}{l}\text { Infrastruktur pada IKM stabil, modern, dan dapat } \\
\text { diandalkan untuk memfasilitasi inovasi sehingga } \\
\text { siap memasuki revolusi industri } 4.0\end{array}$ & \\
\hline \multirow{3}{*}{$\begin{array}{l}\text { Operasi } \\
\text { Pabrik }\end{array}$} & $\begin{array}{l}\text { Sistem rantai pasok IKM berjalan dengan baik } \\
\text { sehingga siap memasuki revolusi industri } 4.0 \text {. }\end{array}$ & \\
\hline & $\begin{array}{l}\text { Proses produksi yang dilakukan IKM sudah otomatis } \\
\text { yang siap memasuki revolusi industri } 4.0\end{array}$ & \\
\hline & $\begin{array}{l}\text { Penyimpanan data yang terpusat dapat mudah } \\
\text { memasuki revolusi industry } 4.0\end{array}$ & \\
\hline
\end{tabular}




\section{HASIL DAN PEMBAHASAN}

\section{Hasil}

Hasil analisis statistik deskriptif Pelaku Industri kecil dan menengah di Kota Blitar adalah sebagai berikut;

Tabel 2. Demographic Profile Of Responden

\begin{tabular}{llcc}
\hline & Demographic & Frequency & Percent (\%) \\
\hline \multirow{4}{*}{ Kecamatan } & Sukorejo & 36 & 37 \\
& Sananwetan & 43 & 44 \\
& Kepanjen Kidul & 18 & 19 \\
\hline \multirow{2}{*}{ Gender } & Laki-laki & 51 & 53 \\
& Perempuan & 46 & 47 \\
\hline \multirow{6}{*}{ Age } & $20-24$ & 3 & 3 \\
& $25-29$ & 7 & 7 \\
& $30-34$ & 11 & 11 \\
& $35-39$ & 22 & 23 \\
& $40-44$ & 22 & 23 \\
& $45-49$ & 21 & 22 \\
& $50-54$ & 7 & 4 \\
\hline \multirow{6}{*}{ Pendidkan } & $55-59$ & 8 & 8 \\
& SD & 17 & 57 \\
& SMP & 55 & 6 \\
& SMA/SMK & 6 & 10 \\
& DIPLOMA & 10 & 1 \\
& Sarjana & 1 & 5 \\
& Magister & $2020)$ & \\
\hline
\end{tabular}

Sumber : Data Primer yang diolah Peneliti (2020)

\section{Uji Data}

Model pengukuran (Outer model) terdiri dari tiga tahap yaitu uji convergen validity, uji validitas diskriminan dan uji reabilitas konsistensi internal. Hasil uji convergen validity dijelaskan pada tabel 3 sebagai berikut:

Tabel 3. Hasil Perhitungan Outer Loading

\begin{tabular}{lcc}
\hline \multicolumn{1}{c}{ Variabel } & Indikator & Outer Loading \\
\hline Manajemen Organisasi (MO) & MO1 & 0,818 \\
\cline { 2 - 3 } & MO2 & 0,888 \\
\cline { 2 - 3 } & MO3 & 0,838 \\
\hline Organisasi dan Budaya (OB) & OB1 & 0,726 \\
\cline { 2 - 3 } & OB2 & 0,865 \\
\hline Produk dan Layanan (PL) & OB3 & 0,897 \\
\cline { 2 - 3 } & PL1 & 0,865 \\
\cline { 2 - 3 } & PL2 & 0,768 \\
\hline Teknologi (TI) & PL3 & 0,796 \\
& TI1 & 0,873 \\
\cline { 2 - 3 } & TI2 & 0,882 \\
\hline Operasi Pabrik (OP) & TI3 & 0,734 \\
\cline { 2 - 3 } & OP1 & 0,781 \\
\cline { 2 - 3 } & OP2 & 0,884 \\
\cline { 2 - 3 } & OP3 &
\end{tabular}

Sumber : Data yang sudah diolah (2020) 
Pada tabel 1 dapat dilihat nilai outer loading >0,70, yang berarti memenuhi syarat rule of thumb dan dapat dikatakan data tersebut adalah valid. Kemudian nilai Average Variance Extracted (AVE) dijelaskan pada tabel 4 berikut;

Tabel 4. Nilai Average Variance Extracted (AVE)

\begin{tabular}{lc}
\hline & Rata-rata Varians Diekstrak (AVE) \\
\hline MO & 0.767 \\
\hline OB & 0.808 \\
\hline PL & 0.705 \\
\hline TI & 0.709 \\
\hline OP & 0.705 \\
\hline
\end{tabular}

Sumber: Data yang sudah diolah (2020)

Dari tabel 4 dapat diketahui bahwa pengukuran AVE pada seluruh variabel dinyatakan valid karena masing-masing memiliki nilai AVE > 0.50. Dengan demikian dapat dinyatakan bahwa setiap variabel telah memiliki discriminant validity yang baik. Kemudian hasil dari uji reliabilitas disajikan pada Tabel 5.

Tabel 5. Hasil Composite Realibility dan Cronbach's Alpha

\begin{tabular}{lcc}
\hline \multicolumn{1}{c}{ Variabel } & $\begin{array}{c}\text { Composit } \\
\text { Reliability }\end{array}$ & $\begin{array}{c}\text { Cronbach's } \\
\text { Alpha }\end{array}$ \\
\hline Manajemen Organisasi (MO) & 0.855 & 0.806 \\
\hline Organisasi dan Budaya (OB) & 0.871 & 0.799 \\
\hline Produk dan Layanan (PL) & 0.852 & 0.742 \\
\hline Teknologi (TI) & 0.903 & 0.839 \\
\hline Operasi Pabrik (OP) & 0.814 & 0.780 \\
\hline
\end{tabular}

Sumber: Data yang sudah diolah (2020)

Tabel 5 menunjukkan nilai composite reliability dan cronbach's alpha untuk semua variabel berada di atas nilai 0,70. Dengan demikian dapat disimpulkan bahwa semua variabel reliabilitas dan memenuhi unsur rule of thumbs. Pada model struktural (Inner Model) didapat hasil Path Coefficient dan R-Square. Nilai Path Coefficientdan R-Square dijelaskan pada gambar berikut: 


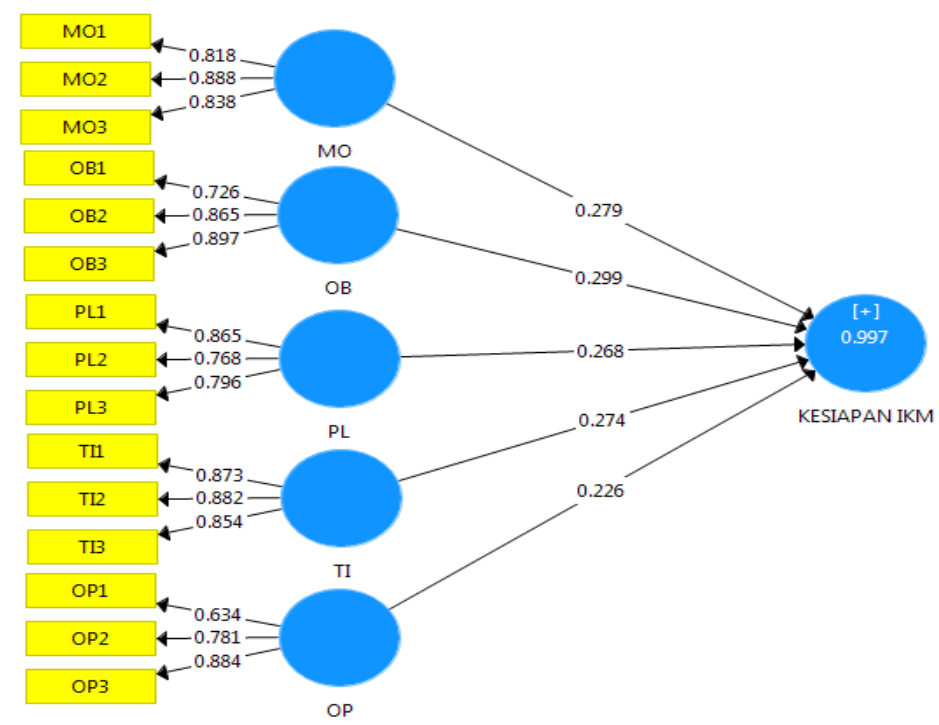

Gambar 2 Hasil Model Struktural (Inner Model) berikut:

Untuk hasil uji hipotesis penelitian ditunjukkan pada tabel 6 sebagai

Tabel 6. Path Analysis

\begin{tabular}{lllll}
\hline Hipotesis & Pengaruh & Effect Type & SRW & Hasil \\
\hline H1 & MO -> Kesiapan IKM & Efek Langsung & 0.279 & Diterima \\
\hline H2 & OB -> Kesiapan IKM & Efek Langsung & 0.299 & Diterima \\
\hline H3 & PL->Kesiapan IKM & Efek Langsung & 0.268 & Diterima \\
\hline H4 & T1 -> Kesiapan IKM & Efek Langsung & 0.274 & Diterima \\
\hline H5 & OP -> Kesiapan IKM & Efek Langsung & 0.226 & Diterima \\
\hline
\end{tabular}

Sumber: Data yang sudah diolah (2020)

\section{PEMBAHASAN}

Pada penelitian ini diberikan lima hipotesis yaitu $\mathrm{H} 1, \mathrm{H} 2, \mathrm{H} 3, \mathrm{H} 4$ dan $\mathrm{H} 5$. Dimana H1 yang menguji jalur regresi antara MO dan Kesiapan IKM hubungan positif dan signifikan, $\mathrm{p}>0.1$ dan $\mathrm{b}=0.279$. H2 yang menguji jalur regresi antara OB dan Kesiapan IKM menunjukkan hubungan positif dan signifikan, $(p>0,1, b=$ 0,299).H3 yang menguji jalur regresi antara PL dan Kesiapan IKM menunjukkan hubungan positif dan signifikan, ( $p>0,1, b=0,268)$. H4 yang menguji jalur regresi antara TI dan Kesiapan IKM menunjukkan hubungan positif dan signifikan, (p> $0,1, \mathrm{~b}=0,274)$.H5 yang menguji jalur regresi antara OP dan Kesiapan IKM menunjukkan hubungan positif dan signifikan, $(p>0,1, b=0,226)$. Kelima hipotesis tersebut saling berkaitan satu sama lain dan kelimanya memiliki pengaruh terhadap kesiapan industri kecil dan menengah. 
Penelitian serupa pernah dilakukan diantaranya Sari, R.P dan Santoso, D.T (2019) dalam penelitiannya mengungkapkan pengembangan model kesiapan UMKM dalam hal ini banyaknya pelaku UMKM berusia muda yang mampu beradaptasi dan menangkap peluang masa kini. Selain itu Ida Farida (2021) dalam penelitiannya menyebutkan bahwa aspek business activity, transaction dan macro environment tidak berpengaruh sedangkan yang berpengaruh adalah aspek marketing, management dan micro environment.

\section{SIMPULAN}

Peneliti menyimpulkan bahwa kelima aspek yaitu Manajemen Organisasi, Organisasi dan Budaya (OB), Produk dan Layanan (PL), Teknologi (TI), Operasi Pabrik (OP) berpengaruh positif dan signifikan terhadap kesiapan IKM dalam menghadapi revolusi industri 4.0. Selain kelima aspek tersebut masih ada beberapa aspek yang dapat digunakan dalam penelitian selanjutnya. Sehingga dalam penelitian selanjutnya dapat diteliti sejauh mana pengaruh aspek-aspek tersebut terhadap kesiapan IKM dalam menghadapi revolusi industri 4.0.

\section{DAFTAR RUJUKAN}

Fathul Wahid, L. I. (2007). Adopsi Teknologi Informasi Oleh Usaha Kecil Dan Menengah Di Indonesia. Seminar, 2007(Snati), 75-79. Retrieved from http://journal.uii.ac.id/index.php/Snati/article/viewFile/1732/1512

Irianto. (2017). Industry 4.0; The Challenges of Tomorrow. Disampaikan Pada Seminar Nasional Teknik Industri,.

Jogiyanto. (2007). Sistem Informasi Keperilakuan (Yogyakarta, ed.). Andi Offset. Kagermann, H., \& Lukas, Wolf-Dieter Wahlster, W. (2011). Industrie 4.0: Mit dem Internet der Dinge auf dem Weg zur 4. industriellen Revolution. Retrieved from http://www.vdi-nachrichten.com/Technik-Gesellschaft/Industrie-40Mit

Kementerian Perindustrian RI. (2017). Empat Strategi Indonesia Masuk Revolusi Industri Keempat. Retrieved from https://kemenperin.go.id/artikel/17565/Empat-Strategi-Indonesia-MasukRevolusi-Industri-Keempat.

Lai, J. Y., Kan, C. W., \& Ulhas, K. R. (2012). Impacts of employee participation and trust on e-business readiness, benefits, and satisfaction. Information Systems and E-Business Management, 11(2), 265-285. https://doi.org/10.1007/s10257-012-0193-9

OECD. (1993). Small and Medium-sized Enterprises: Technology and Competitiveness. Paris: Organisation for Economic Cooperation and Development.

Sani, A., Subiyakto, A., \& Rahman, T. K. A. (2018). Integration of the Technology Readiness and Adoption Models for Assessing IT Use among SMEs in Indonesia. 
https://doi.org/10.13140/RG.2.2.32673.86885/1

Sani, A., \& Wiliani, N. (2019). Faktor Kesiapan Dan Adopsi Teknologi Informasi Dalam Konteks Teknologi Serta Lingkungan Pada Umkm Di Jakarta. JITK (Jurnal Ilmu Pengetahuan Dan Teknologi Komputer), 5(1), 49-56. https://doi.org/10.33480/jitk.v5i1.616

Sommer, L. (2015). Industrial Revolution - Industry 4 . 0: Are German Manufacturing SMEs the First Victims of this Revolution ?8(5), 1512-1532.

Stentoft, J., Jensen, K. W., Philipsen, K., \& Haug, A. (2019). Drivers and Barriers for Industry 4.0 Readiness and Practice: A SME Perspective with Empirical Evidence. Proceedings of the 52nd Hawaii International Conference on System Sciences, 6, 5155-5164. https://doi.org/10.24251/hicss.2019.619

Sulistyastuti, D. R. (2004). Dinamika Usaha Kecil Dan Menengah (UKM) Analisis Konsentrasi Regional UKM di Indonesia 1999-2001. Jurnal Ekonomi Pembangunan, 9 No 2, 143-164. Retrieved from https://journal.uii.ac.id/JEP/article/view/617/543

Farida, Ida. (2021). Kesiapan Usaha Mikro, Kecil dan Menengah Industri Batik Tegalan Untuk Menghadapi Revolusi Industri 4.0. Jurnal MONEX, 10 No. $1,10-15$ http://www.ejournal.poltektegal.ac.id/index.php/monex/article/view/2151

Sari, R.P., Santoso, D.T. 2019. Pengembangan Model Kesiapan UMKM di Era Revolusi Industri 4.0. Jurnal Media Teknik dan Sistem Industri, Vol. 3, No. $1,37-42$. 